\title{
NUMERICAL AND EXPERIMENTAL STUDY ON LANDSLIDE DAM FAILURE BY SLIDING
}

\author{
Ripendra AWAL ${ }^{1}$, Hajime NAKAGAWA ${ }^{2}$, Yasuyuki BABA ${ }^{3}$ and Raj Hari \\ SHARMA 1 \\ ${ }^{1}$ Student Member of JSCE, Graduate Student, Graduate School of Civil and Earth Resources Engineering, Kyoto \\ University (Yoshida-Honmach, Sakyo-ku, Kyoto 606-8501, Japan) \\ ${ }^{2}$ Member of JSCE, Dr. of Eng., Professor, Disaster Prevention Research Institute, Kyoto University (Shimomisu, \\ Yoko-oji, Fushimi-ku, Kyoto 612-8235, Japan) \\ ${ }^{3}$ Member of JSCE, Dr. of Eng., Assistant Professor, Disaster Prevention Research Institute, Kyoto University \\ (Shimomisu, Yoko-oji, Fushimi-ku, Kyoto 612-8235, Japan)
}

\begin{abstract}
Landslides and debris flows due to heavy rains or earthquakes may block a river flow and create landslide dam naturally. Landslide dams may fail by erosion due to overtopping, abrupt collapse of the dam body or progressive failure. The peak discharge produced by abrupt collapse of the dam is very high compared with other types of failure. However, in-depth knowledge of the mechanism of the dam failures and measured data are still lacking. Numerical simulation and flume experiments were performed to investigate the mechanism of landslide dam failure due to sliding. A stability model coupled with a seepage flow model was used for numerical simulation. Comparison result of numerical simulation and experimental measurement is quite close in terms of movement of moisture in the dam body, predicted critical slip surface and time to failure of the dam body. It shows the potential of the numerical model to be extended for the prediction of flood/debris flow hydrograph by abrupt collapse of the landslide dam.
\end{abstract}

Key Words : landslide dam, slope stability, seepage flow, numerical simulation, laboratory experiment

\section{INTRODUCTION}

Landslides and debris flows due to heavy rains or earthquakes may block river flow and create landslide dam naturally. About $84 \%$ of the landslide dams are formed by excessive precipitation (rain storms and rapid snowmelt) and strong earthquakes ${ }^{1)}$. A landslide dam is made up of a heterogeneous mass of unconsolidated or poorly consolidated material. It differs from constructed embankment dam in that it has no water barrier, filter zones and drain zones and it also has no channelized spillway. In general, shapes of landslide dams are triangular without flat crest. Nearly all upstream and downstream faces of landslide dams are at the angle of repose of the material or shallower and the dams are much wider than their height. Apart from inundation of upstream areas the failure of the dam may generate debris flow causing major flooding, sediment hazard, loss of lives and properties in the downstream. Landslide dams may fail by the erosive destruction due to overtopping, abrupt collapse of the dam body or progressive failure $^{2)}$. Landslide dams most commonly fail by overtopping, followed by breaching from erosion by the overtopping water. Although abrupt collapse of the dam body is not common, the peak discharge produced by such failure is very high compared with other types of failures. If the infiltration rate of the dam body is very large and strength of the dam body is small, instantaneous slip failure may occur. However, in-depth knowledge of the mechanism of the dam failures and measured data are still lacking. A simulation model of the dam failure processes will therefore be useful.

The main objective of this study is to predict the failure of landslide dam due to sudden sliding through flume experiments and numerical simulation. A stability model coupled with a seepage flow model was used to determine moisture movement in the dam body, time to failure and geometry of failure surface.

\section{NUMERICAL MODEL}


The model of the dam failure due to sliding consists of two models. The seepage flow model calculates pore water pressure and moisture content inside the dam body. The model of slope stability calculates the factor of safety and the geometry of critical slip surface according to pore water pressure and moisture movement in the dam body.

\section{(1) Model of seepage flow}

The seepage flow in the dam body is caused by the blocked water stage behind the dam. The transient flow in the dam body after formation of landslide dam can be analyzed by Richards' equation. To evaluate the change in pore water pressure in variably saturated soil, pressure based Richards' equation is used ${ }^{3)}$.

$$
C \frac{\partial h}{\partial t}=\frac{\partial}{\partial x}\left(K_{x}(h) \frac{\partial h}{\partial x}\right)+\frac{\partial}{\partial z}\left(K_{z}(h)\left(\frac{\partial h}{\partial z}+1\right)\right)(1)
$$

where $h$ is the water pressure head, $K_{x}(h)$ and $K_{z}(h)$ are the hydraulic conductivity in $x$ and $z$ direction, $C$ is the specific moisture capacity $(\partial \theta / \partial h), \theta$ is the soil volumetric water content, $t$ is the time, $x$ is the horizontal spatial coordinate and $z$ is the vertical spatial coordinate taken as positive upwards. Eq.(1) represents flow in both the unsaturated domain as well as in the saturated domain. Richards' equation is a non-linear parabolic partial differential equation in the unsaturated zone and elliptic in the saturated zone. Line-successive over-relaxation (LSOR) is often a very effective method of treating cross-sectional problem grids. LSOR scheme is used in this study for the numerical solution of Richards' equation ${ }^{4)}$.

In order to solve Richards' equation, the constitutive equations, which relate the pressure head to the moisture content and the relative hydraulic conductivity, are required ${ }^{5)}$. In this study, following constitutive relationships proposed by van Genuchten (1980) are used for establishing relationship of $K-h$ and $\theta-h$, with $m=1-(1 / \eta)$.

$$
\begin{gathered}
S_{e}=\left\{\begin{array}{cc}
\frac{1}{\left(1+|\alpha h|^{\eta}\right)^{m}} & \text { for } h<0 \\
1 & \text { for } h \geq 0
\end{array}\right. \\
K=\left\{\begin{array}{cc}
K_{s} S_{e} 0.5\left[1-\left(1-S_{e}^{1 / m}\right)^{m}\right]^{2} & \text { for } h<0 \\
K_{s} & \text { for } h \geq 0 \\
S_{e}=\frac{\theta-\theta_{r}}{\theta_{s}-\theta_{r}} &
\end{array}\right.
\end{gathered}
$$

where, $K_{s}$ is the saturated hydraulic conductivity, $\alpha$ and $\eta$ are parameters related with matric potential of soil and are measure of capillary fringe thickness and pore size distribution of soil respectively, $S_{e}$ is the effective saturation, $\theta_{s}$ and $\theta_{r}$ are saturated and residual moisture content respectively.

\section{(2) Model of slope stability}

The method of slices is one of the widely used limit equilibrium method for the analysis of the stability of slopes. The sliding mass is divided into a number of vertical slices. The static equilibrium of the slices and the mass as a whole are used to solve the problem. All methods of slices are statically indeterminate and involve assumptions in order to make the problem statically determinate. Analysis techniques differ from each other in respect of the equilibrium equations employed and the particular assumptions made with regards to the inter-slice forces.

Many attempts have been conducted to locate the position of critical slip surface by using general noncircular slip surface theory coupled with different non-linear programming methods. Baker (1985) combined the Spencer method with dynamic programming ${ }^{6}$, Naguen (1985) used simplex method $^{7)}$, Arai and Tagyo (1985) used the conjugate gradient method ${ }^{8)}$, Yamagami and Ueta (1986) coupled the Janbu's simplified method with dynamic programming involving Baker's ideas ${ }^{9)}$, Yamagami and Ueta (1988) performed a comparative study by combining several optimization methods with the Morgenstern-Price $\operatorname{method}^{10)}$.

The numerical procedure behind the identification of critical noncircular slip surface with the minimum factor of safety based on dynamic programming and the Janbu's simplified method is mainly based on research by Yamagami and Ueta ${ }^{9}$. The algorithm combines the Janbu's simplified method with dynamic programming on the basis of Baker's successful procedure.

Janbu's simplified method can be used to calculate the factor of safety for slip surfaces of any shape. The sliding mass is divided into vertical slices and the static equilibrium conditions of each slice are considered as sum of the vertical forces equal to zero and sum of the forces parallel to failure surface equal to zero. For the soil mass as a whole, sum of the vertical forces $\sum F_{y}=0$ and sum of the horizontal forces $\sum F_{x}=0$ are considered as equilibrium condition.

Based on the above considerations the factor of safety, $F_{s}$ for Janbu's simplified method is defined as:

$$
F_{s}=\frac{1}{\sum_{i=1}^{n} W_{i} \tan \alpha_{i}}
$$




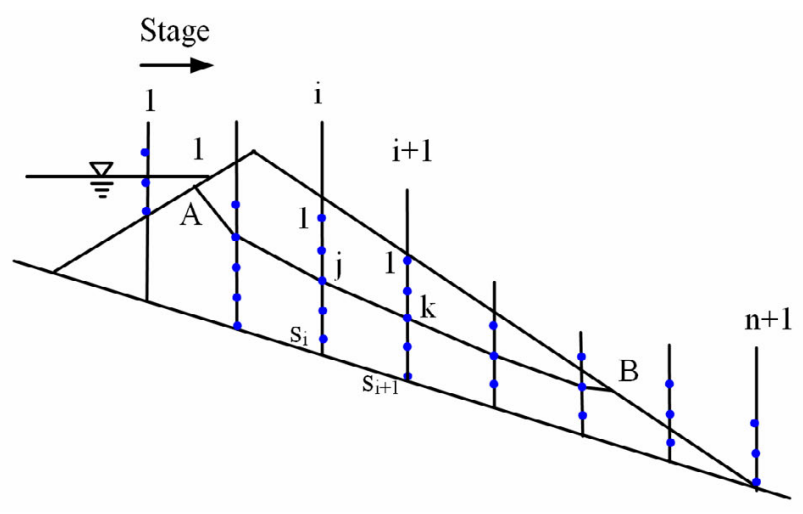

Fig.1 Schematic representation of stages, states and slip surface

$$
\times \sum_{i=1}^{n}\left\{\frac{c l_{i} \cos \alpha_{i}+\left(W_{i}-u_{i} l_{i} \cos \alpha_{i}\right) \tan \phi}{\cos ^{2} \alpha_{i}\left(1+\frac{1}{F_{s}} \tan \alpha_{i} \tan \phi\right)}\right\}
$$

where $W_{i}$ is the weight of each slice including surface water, $l_{i}$ is the length of the base of each slice, $u_{i}$ is the average pore water pressure on the base of the slice, $\alpha_{i}$ is the inclination of the base to the horizontal, $n$ is the total number of slices, and $c$ and $\phi$ are the Mohr-Coulomb strength parameters.

Eq.(5) can be generalized as

$$
F_{s}=\frac{\sum R_{i}}{\sum T_{i}} \quad(i=1 \sim n)
$$

where,

$$
\begin{gathered}
R_{i}=\frac{c l_{i} \cos \alpha_{i}+\left(W_{i}-u_{i} l_{i} \cos \alpha_{i}\right) \tan \phi}{\cos ^{2} \alpha_{i}\left(1+\frac{1}{F_{s}} \tan \alpha_{i} \tan \phi\right)} \\
T_{i}=W_{i} \tan \alpha_{i}
\end{gathered}
$$

The factor of safety, defined in Eq.(6), can be minimized by the introduction of the 'auxiliary function', $G$, and minimization of $F_{s}$ is equivalent to minimizing the function $G$.

$$
G=\sum_{i=1}^{n}\left(R_{i}-F_{s} T_{i}\right)
$$

When applying dynamic programming, minimization of $G$ is carried out over all admissible slip surfaces:

$$
G_{m}=\min G=\min \left[\sum_{i=1}^{n}\left(R_{i}-F_{s} T_{i}\right)\right]
$$

where, $G_{m}$ is the minimum of the function $G$, which yields the critical slip surface. $F_{s}$ in Eq.(10) is not known in advance, so that starting with an initial assumed value of $F_{s}$, we must iterate the computation process. As shown in Fig. 1, an orbitary line $j k$ which connects points $(i, j)$ and $(i+1, k)$ is considered as a part of assumed slip surface. $R_{i}$ and $T_{i}$ on the surface $j k$ are obtained

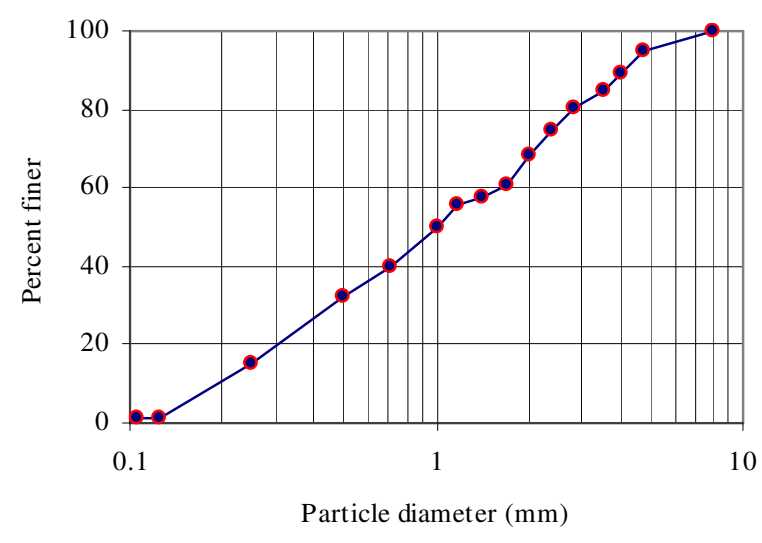

Fig.2 Grain size distribution of sediment mix

Table 1 Some parameters of the sediment considered

\begin{tabular}{lc} 
Sediment type & SMix \\
\hline Saturated moisture content, $\theta_{\text {sat }}$ & 0.287 \\
Residual moisture content, $\theta_{\text {res }}$ & 0.045 \\
$\alpha$ & 5.50 \\
$\eta$ & 3.20 \\
Saturated hydraulic conductivity, $\mathrm{K}_{\text {sat }}$ & 1440 \\
(mm/hr) & \\
Specific gravity, Gs & 2.65 \\
Mean grain size, $\mathrm{D}_{50}(\mathrm{~mm})$ & 1.00 \\
Angle of repose, $\phi($ degree $)$ & 34 \\
\hline
\end{tabular}

from Eq.(7) and Eq.(8) and the return function is calculated using Eq.(11).

$$
D G_{i}(j, k)=R_{i}-F_{s} T_{i}
$$

If $H_{i}(j)$ is the minimum value of $G$ from the point $A$ (Fig. 1) to the point $(i, j)$, then the minimum $G$ value from $A$ to $(i+1, k)$ is given by Eq.(12).

$$
\begin{gathered}
H_{i+1}(k)=\min \left[H_{i}(j)+D G_{i}(j, k)\right] \\
i=1 \sim n, j=1 \sim S_{i}, k=1 \sim S_{i+1}
\end{gathered}
$$

The boundary conditions are

$$
H_{1}(j)=0, j=1 \sim S_{1}
$$

$$
G_{m}=\min G=\min \left[H_{n+1}(j)\right]\left(j=1 \sim S_{i+1}\right)
$$

Difference between the value of $F_{s}$ calculated by Eq.(6) after this procedure and initially assumed value of $F_{s}$ should be within tolerance, therefore, iteration is required to obtain exact value of $F_{s}$ along the slip surface.

The Janbu's simplified method uses a correction factor $f_{o}$ to account for the effect of the interslice shear forces. However, in this study correction factor is not considered since the range of correction factor for non-cohesive soil is small. 


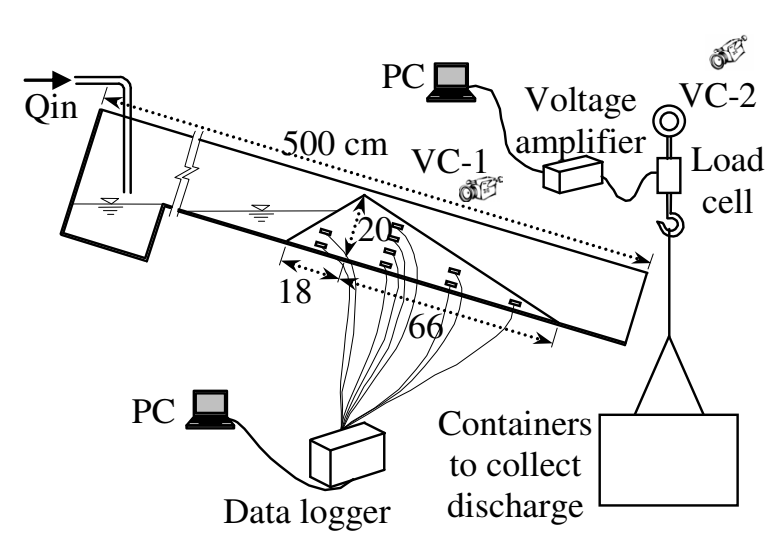

Fig.3 Experimental setup

\section{LAB EXPERIMENT}

A rectangular flume of length $5 \mathrm{~m}$, width $20 \mathrm{~cm}$ and depth $21 \mathrm{~cm}$ was used. The slope of the flume was set at 17 degree. Silica sand S1, S2, S3, S4, S5, $\mathrm{S} 6$ and $\mathrm{S} 7$ are mixed in equal portion to make the mixed sediment for dam body. The grain size distribution of sediment mixture is shown in Fig. 2. The mean diameter of the sediment mixture was $1 \mathrm{~mm}$. van Genuchten parameters (including $\theta_{r}$ ) were estimated by non-linear regression analysis of soil moisture retention data obtained by $\mathrm{pF}$ meter experiment. Some other parameters of mixed sand are listed in Table 1.

The shape and size of landslide dam, grain size distribution, degree of compaction and moisture content of landslide dam material depend on the site condition and the process that have triggered dam forming landslides. However for simplicity, in this experiment, triangular dam of homogeneous material with uniform compaction and uniform initial moisture content was used. Triangular dam was prepared on the rigid bed of flume by placing mixed sand on the flume. The upstream and downstream faces of landslide dam are slightly shallower than the angle of repose of the sand mixture. The height of the dam was $20 \mathrm{~cm}$ and the longitudinal base length was $84 \mathrm{~cm}$. The schematic diagram of the flume is shown in Fig. 3. To measure the movement of dam slope during sliding, red colored sediment strip was placed in the dam body at the face of flume wall. A digital video camera was placed on the side of the flume to capture the shape of slip surface due to sudden sliding. Water level of reservoir was kept constant in case I; where as steady discharge was supplied in case II. Temporal weight of debris flow was also measured in the downstream end of the flume with the help of load cell. The shape of slip surface during sliding of the dam body was measured by analyses of video taken from the flume side.

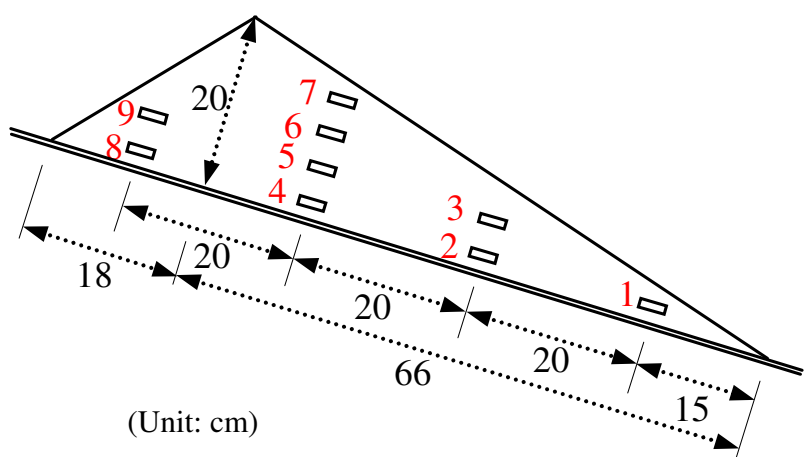

Fig.4 Arrangement of WCRs (1-9).

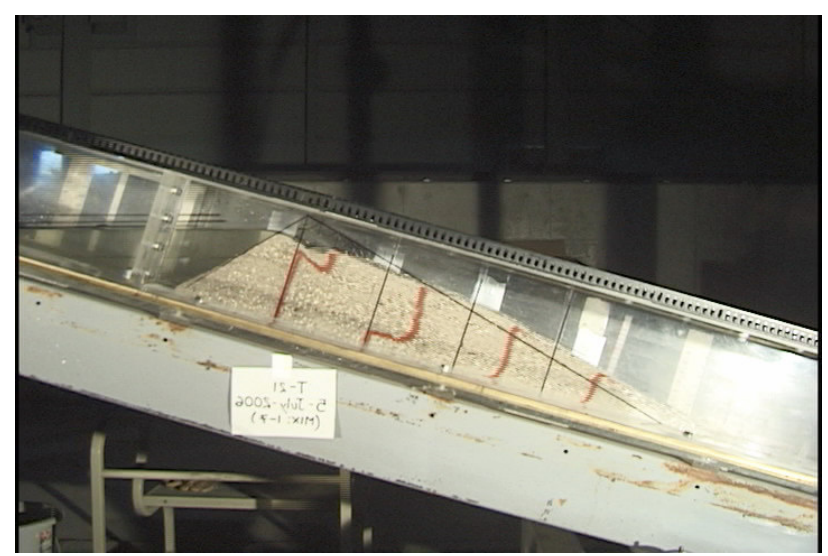

Fig. 5 Slope sliding of dam in constant water level in reservoir

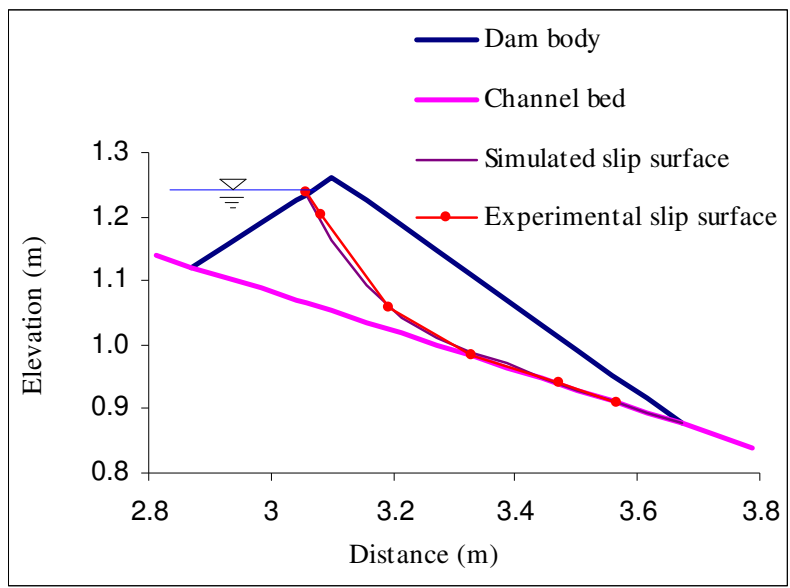

Fig. 6 Comparison of simulated and experimental slip surface

For both cases, water content reflectometers (WCRs) were used to measure the temporal variation of moisture content during seepage process. Nine WCRs were inserted inside the dam body from a sidewall of the flume. The arrangements of WCRs are shown in Fig. 4. The data acquisition interval for WCRs was $1 \mathrm{sec}$. The probe rods disturb the sliding of the dam body so water content was measured in separate experiment under same experimental conditions.

All the WCRs were calibrated prior to the experiment. The relationship between volumetric water content and output period of WCR was represented by different linear equation for different 

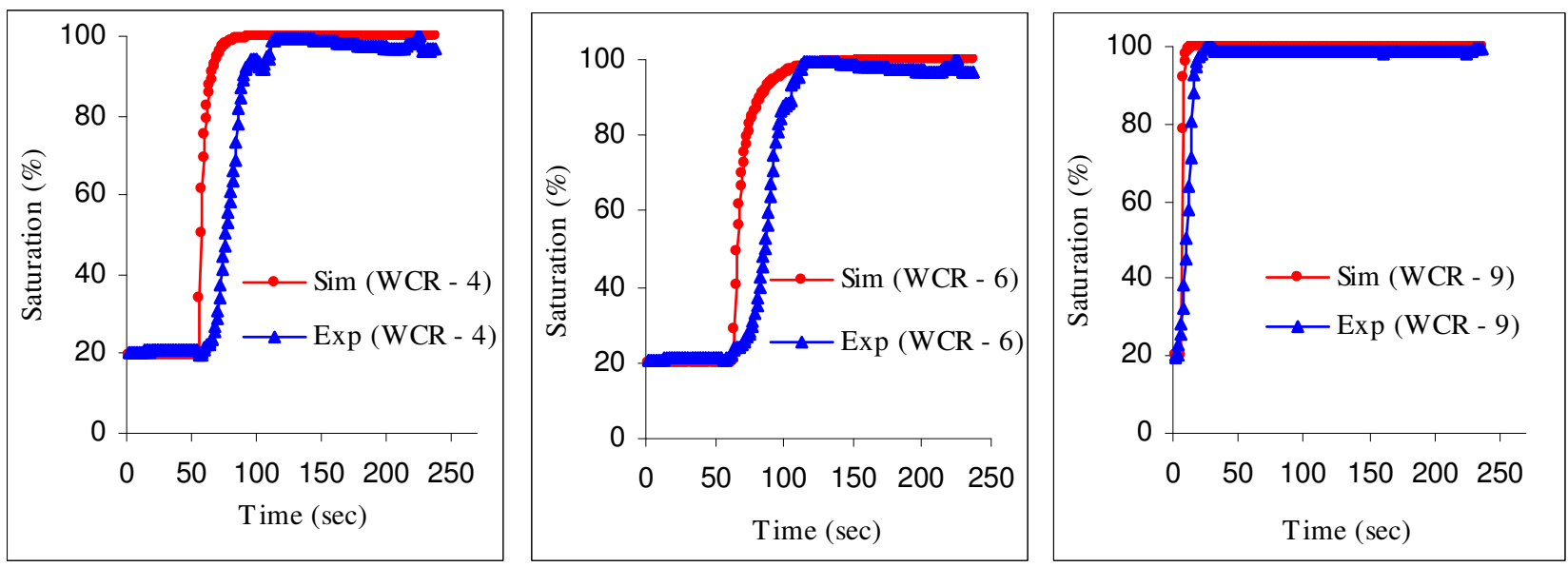

Fig.7 Simulated and experimental results of water content profile for constant water level in reservoir (WCR - 4, 6 and 9)

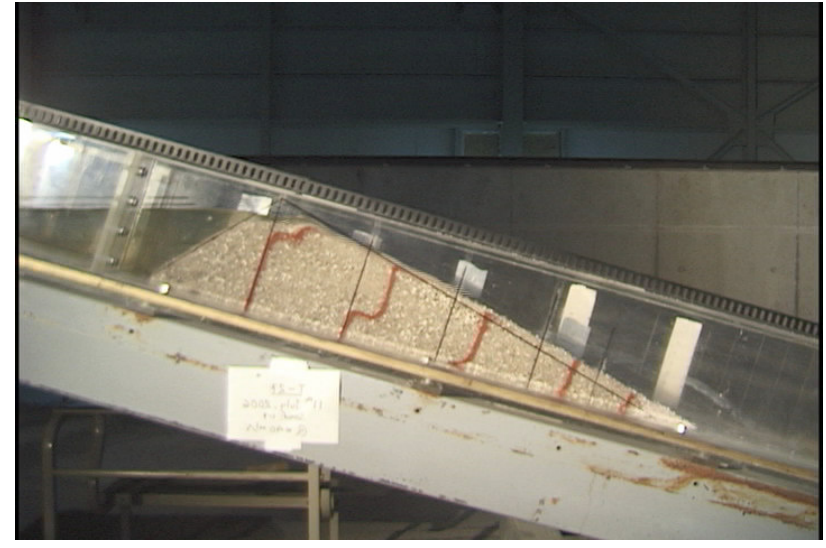

Fig.8 Slope sliding of dam in steady discharge in reservoir

WCR. $\mathrm{pF}$ meter with automatic pressure controller was used to determine the van Genuchten parameter of sand mixture used for the landslide dam.

\section{RESULT AND DISCUSSION}

A high water level or rise of water level in the reservoir causes water to penetrate into the dam body and it increases both ground water pressures and weight of the dam body. Sliding of the dam body occurs when the mobilized shear stress which is increased by the weight increase of the dam body becomes larger than resisting shear stress which is decreased by the increase of the water pressures.

Many experiments were performed to observe the failure of the dam by sudden sliding.

\section{Case I: Constant water level in reservoir}

The reservoir in the upstream of the dam was filled by water up to $16 \mathrm{~mm}$ below crest level of the dam in 25 seconds. Then water level was maintained constant. Sudden sliding of the dam was observed at $255 \mathrm{sec}$. Fig. 5 shows the observed sliding surface in the experiment. The slip surface

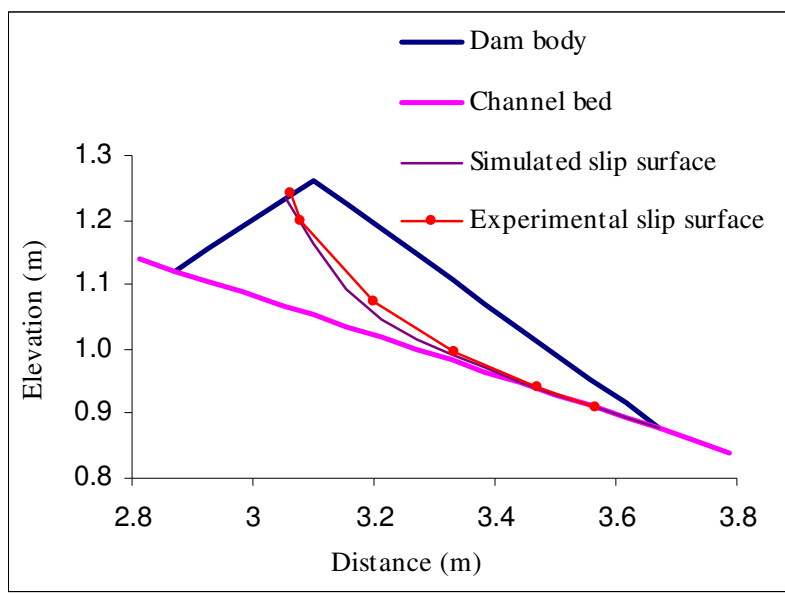

Fig.9 Comparison of simulated and experimental slip surface

was determined by the measurement of tilting of the red color strips with the help of snaps captured by the video camera positioned on the side of flume. Fig. 6 shows simulated and experimental slip surface. The simulated failure time was $237 \mathrm{sec}$ after start of filling of reservoir. The simulated time was slightly earlier than the experimentally observed time that may be due to the assumption of immobile air phase in unsaturated flow and variation of saturated hydraulic conductivity since it was difficult to make sand mixture perfectly homogeneous.

Same experimental conditions were used to measure moisture content in the dam body using WCRs. Simulated and experimental results of variation of moisture content at WCR-4, WCR-6 and WCR-9 are shown in Fig. 7. The results of numerical simulation of moisture profile in the dam body are in good agreement with the experimental results.

\section{Case II: Steady discharge in reservoir}

Steady discharge of $39.8 \mathrm{~cm}^{3} / \mathrm{sec}$ was supplied from the upstream end of the flume. The sliding 

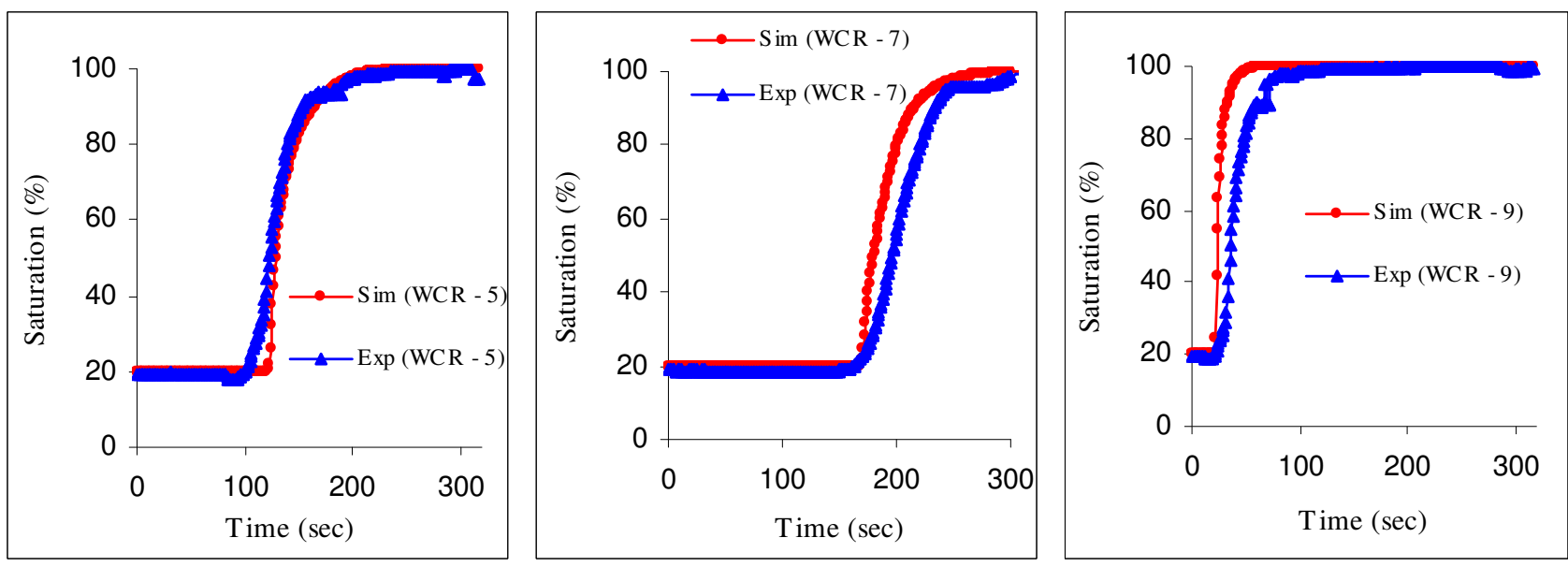

Fig.10 Simulated and experimental results of water content profile for steady discharge in reservoir (WCR $-5,7$ and 9)

surface observed in the experiment is shown in Fig. 8. The sliding of the dam body was observed at $350 \mathrm{sec}$ in the experiment whereas in the simulation it was observed at $317 \mathrm{sec}$. Fig. 9 shows the comparison of simulated and experimental slip surface.

For the same experimental conditions, moisture content in the dam body was measured by using WCRs. Fig. 10 shows the simulated and experimental results of moisture profile at WCR-5, WCR-7 and WCR-9 which are quite close.

The numerical simulation and experimental results of moisture profile are in good agreement for both cases. The geometry of predicted critical slip surface was also similar to that observed in the experiment. So the model developed by coupling the seepage flow model with the stability model in this study is promising.

\section{CONCLUSION}

Sudden failure of landslide dam was studied in experimental flume for constant head and steady discharge in the upstream reservoir. A high constant water level or gradual rise of water level in the reservoir causes water to penetrate into the dam body and it increases mobilized shear stress and dam fails by sudden collapse when it becomes larger than resisting shear stress. The numerical simulation and experimental results of movement of moisture in the dam body, predicted critical slip surface and time to failure of the dam body are in good agreement. The failure time can also be predicted by numerical model so it has great potential to extend for the prediction of flood/debris flow hydrograph by abrupt collapse of landslide dam.

ACKNOWLEDGMENT: The scholarship provided by the Monbukagakusho (Ministry of Education, Culture, Sports, Science and
Technology, Japan) to the first author is gratefully acknowledged.

\section{REFERENCES}

1) Schuster, R.L., and Costa, J.E.: A perspective on landslide dams, in Schuster, R.L., ed., Landslide Dams: Processes, Risk, and Mitigation: ASCE Geotechnical Special Publication No. 3, pp.1-20, 1986.

2) Takahashi T.: Debris flow, Monograph Series of IAHR, Balkema, pp.1-165, 1991.

3) Sharma, R. H., Nakagawa, H.: Predicting timing and location of rainfall triggering shallow landslides, Annual J. of Hydraulic Engineering, JSCE, Vol.49, pp.43-48, 2005.

4) Freeze, R. A.: Mathematical models of hillslope hydrology, in Kirkby, M. J., ed., Hillslope Hydrology, John Wiley, pp. 177-225, 1976.

5) Sharma, R. H., Nakagawa, H., Baba, Y., Muto, Y. and Ano, M.: Laboratory experiments on moisture content variation and landslides caused by transient rainfall, Annual J. of Hydraulic Engineering, JSCE, Vol.50, pp.151-156, 2006.

6) Baker, R.: Determination of the critical slip surface in slope stability computations, International Journal for Numerical and Analytical Methods in Geomechanics, Vol.4, pp.333-359, 1980.

7) Nguyen, V. U.: Determination of critical slope failure surfaces, Journal of Geotechnical Engineering,, ASCE, Vol. 111(2) pp.238-250, 1985.

8) Arai, K. and Tagayo, K.: Determination of noncircular slip surface giving the minimum factor of safety in slope stability analysis, Soils and Foundations, Vol. 25(1), pp.43-51, 1985.

9) Yamagami, T. and Ueta, Y.: Noncircular slip surface analysis of the stability of slopes: An application of dynamic programming to the Janbu method, Journal of Japan Landslide Society, Vol. 22(4), pp.8-16, 1986.

10) Yamagami, T. and Ueta, Y.: Search for noncircular slip surfaces by the Morgenstern-Price Method, In Proceedings of the $6^{\text {th }}$ International Conference on Numerical Methods in Geomechanics, Innsbruck, pp.1335-1340, 1988.

(Received September 30, 2006) 